\title{
MECANISMOS SOCIAIS DA REFORMA AGRÁRIA EM SÃO PAULO PELO VIÉS ETNOGRÁFICO*
}

\author{
Nashieli Rangel Loera \\ Faculdade de Filosofia e Ciências da UNESP e Centro de Estudos Rurais - Universidade Estadual \\ de Campinas (Unicamp), Campinas, SP - Brasil.<nashieliralo@gmail.com>
}

http://dx.doi.org/10.1590/ 0102-6445027-056/95

No Brasil, as ocupações de terra e a montagem de acampamentos organizados por movimentos são uma maneira de reivindicar do Estado demandas sociais, nesse caso, desapropriação de terras para fins de reforma agrária. Para os participantes das ocupações, o ato de montar uma barraca em um acampamento é a forma de dizer que é candidato à reforma agrária, mas também é a forma apropriada de dizer que é essa a terra ou o espaço físico que se pretende que seja desapropriado.

Em outro trabalho (Loera, 2006), ao analisar os mecanismos sociais que permitem a reprodução dos acampamentos,

\footnotetext{
* Uma versão preliminar deste artigo foi apresentada na Reunião de Antropologia do Mercosur em 2011 no GT "Tramas políticas colectivas, espacios de gobierno y vida cotidiana" e faz parte dos resultados do projeto de pesquisa As formas de acampamento, financiado pela Fundação de Amparo à Pesquisa do Estado de São Paulo (Fapesp) na modalidade Jovem pesquisador $\left(\mathrm{n}^{\circ}\right.$ de processo 2010/023316). A pesquisa de campo foi realizada em acampamentos de sem terra organizados por diferentes movimentos em diversas regiões do Estado de São Paulo, assim como em acampamentos indígenas localizados no sul deste estado e no Mato Grosso do Sul. Agradeço ao Instituto de Terras do Estado de São Paulo (Itesp), que disponibilizou, para o desenvolvimento do projeto, os documentos e atas das comissões de seleção referenciadas neste artigo.
} 
mencionei que um acampamento está sempre vinculado a outro em formação ou já formado, e este, por sua vez, se encontra vinculado a um assentamento. São os indivíduos, os ocupantes desses espaços que, cumprindo com uma série de obrigações e compromissos para com o movimento que organiza a ocupação, convidam outros para formarem novos acampamentos e mais: eles mesmos participam de novas ocupações, mostrando para os novos acampados a tecnologia de montagem e organização dos acampamentos.

Por outro lado, hoje em dia, estar acampado ou participar de uma ocupação significa também estar na reforma (agrária), expressão usada principalmente por aqueles que já foram beneficiados com um lote de terra, mas que continuam cumprindo com seus compromissos para com o movimento ao participarem de novas ocupações e acampamentos.

Estar na reforma traduz também o tempo de acampamento ${ }^{1}$. 28 Esse "tempo" é muito mais do que uma medida cronológica, pois não é somente uma forma de quantificar o tempo que se passa ou se passou em um acampamento, debaixo da lona, mas também o número de ocupações, acampamentos e mobilizações das quais o indivíduo participou, quanto sofreu nesse processo, a dedicação ao acampamento e ao movimento, a lealdade demonstrada, as relações estabelecidas com outros movimentos, com autoridades locais e representantes do Estado, e também é uma expressão que traduz o conhecimento ou know how que se tem do modo de funcionamento do mundo dos acampamentos sem-terras. $\mathrm{O}$ tempo de acampamento é assim um princípio organizador e ordenador das relações sociais nesse mundo social. Inspirada em Tempo de Brasília, de Antonádia Borges (2003), diria que o tempo de acampamento é também uma fórmula social que serve para classificar para quem o Estado distribuirá terras.

1 Daqui em diante termos nativos aparecerão em itálico. 
Para Borges (2003), o "tempo de Brasília" é uma categoria nativa que se tornou um critério que orienta a concessão de benefícios dados pelo governo do Distrito Federal a determinado tipo de população. Conforme a autora, para receber esses diversos benefícios ofertados pelo governo local em forma de "dons", "a população é hierarquizada num ranking de merecimento" (Borges, 2004, p. 25). O "tempo de Brasília", como comprovante do tempo de residência em Brasília, seria uma das fórmulas mágicas através das quais se calcula o quantum de merecimento da população. Nas palavras da autora:

O "tempo de Brasília", embora seja somente uma das variáveis que compõem a equação que fornecerá o número de pontos de cada indivíduo inscrito para o recebimento de benefícios estatais, acaba dando nome e sentido a todo o processo social em que é necessário envolver-se para alcançar esse pertencimento local (Borges, 2004, p. 26).

Para os movimentos sem-terras, representados pelas lideranças dos acampamentos, o tempo de acampamento também pode determinar, para cada acampamento, quais critérios contaram mais na hora da seleção das famílias que irão receber um lote: se são moradores ou não do acampamento, se participam das lutas ou jornadas, se realizam tarefas nos acampamentos.

Como mostrei em outros textos (Loera, 2010, 2011 e 2013), o tempo de acampamento pode ter diversos significados, todos eles referidos ao contexto, à situação, assim como às posições que as pessoas ocupam nesse mundo social particular. Os participantes do mundo das ocupações fazem referência a expressões como tempo de barraco, tempo de luta $\mathrm{e}$ tempo de reforma, como homônimas ao tempo de acampamento; no entanto, descrevem, na maioria das vezes, uma diversidade de significados, ações e situações. 
Minha hipótese é que o tempo de acampamento, como mecanismo de seleção de famílias no mundo das ocupações de terra tem sido constituído na relação com os órgãos do Estado encarregados da desapropriação de terras, e é na dinâmica dessa relação que vai sendo modelado pelos próprios movimentos e vai tomando outros significados.

No caso de alguns acampamentos do Estado de São Paulo, esse mecanismo de seleção passa pela relação que se tem com o Itesp (Instituto de Terras do Estado de São Paulo), órgão ligado ao governo estadual cuja função principal é mediar os conflitos por terra no estado e, dependendo do estatuto da área em disputa, direcionar a distribuição de lotes. Esse órgão, em caso de a terra em disputa ser de domínio estadual, está encarregado de montar uma Comissão de Seleção conformada por representantes do governo e representantes da sociedade civil. Dependendo da configuração dessa comissão, o tempo de acampamento pode figu30 rar, junto com outros, como o tempo de município, tempo de agricultura etc., na lista dos critérios que pontuam e configuram o perfil das famílias que serão beneficiadas com um lote de terra. Esse perfil vai sendo "modelado" no processo de acampamento como uma maneira de as famílias cumprirem com os critérios preestabelecidos pela comissão. As famílias acampadas, nesse processo aprendem também qual a maneira "adequada" de se relacionar com o Estado.

A evidência da existência de relações de cooperação entre Estado e movimentos no cotidiano dos acampamentos permite questionar afirmações de senso comum, como a que diz que existiria um confronto entre eles ou que a reforma agrária como política de distribuição de terras seria um processo vertical realizado unicamente pelo Estado.

Existem mecanismos de cooperação entre grupos e instituições que, como mencionam Grimberg, Fernández e Rosa (2009), são vistos como antagônicos, porém, inclusive mantêm obrigações recíprocas. Essa cooperação entre Estado e 
movimentos pode se intensificar dependendo também do contexto, das relações que se estabelecem entre representantes dos movimentos e representantes dos órgãos que mediam a distribuição das terras, e depende também de conjunturas políticas e sociais específicas.

A meu ver, no mundo dos acampamentos é a perspectiva etnográfica a que nos permite evidenciar melhor esses mecanismos de classificação e cooperação e as condições sociais que permitem a reprodução de um modelo de demanda social, como é a "forma acampamento" (Sigaud, 2000), assim como suas variações ou o que tenho chamado, retomando uma expressão nativa, de formas de acampamento.

Nesse sentido, concordo com Macedo (2003, p. 10), quando menciona que, ao estudarmos os acampamentos, há que levar em conta as relações com a política local e os órgãos do governo, pois "as dinâmicas sociais desenvolvidas nos acampamentos só podem ser compreendidas quando relacionadas ao quadro institucional que as envolvem”.

Nesta ocasião, analisarei etnograficamente a dinâmica de organização e configuração de acampamentos liderados pelo Movimento dos Trabalhadores Rurais Sem Terra (MST) na região do Pontal de Paranapanema, a oeste do Estado de São Paulo, região com maior número de acampamentos sem-terras do estado.

Como irei mostrar, determinadas condições e normas exigidas para manter uma barraca no acampamento, assim como a circulação e redistribuição das famílias entre acampamentos formam parte do processo de configuração dos mecanismos sociais de produção da reforma agrária em São Paulo.

Meu objetivo também será o de mostrar que as relações de cooperação estabelecidas entre representantes do Estado, de governos locais e dos movimentos são fundamentais no processo de distribuição de dons do Estado, no caso aqui analisado, um lote de terra, mas também essas relações são condições sociais fundamentais para a configuração das formas de acampamento. 


\section{Formas de acampamento}

Apesar de os acampamentos se configurarem como um modelo de demanda, uma "forma acampamento", como demonstrado por Sigaud (2000), eles estão constituídos por características próprias que conformam variações desse modelo e que dependem do movimento que organiza o acampamento, das trajetórias sociais dos militantes e dirigentes envolvidos com a organização deles, da origem e das características das famílias que se instalam debaixo da lona, das características da região onde os acampamentos são montados e das características da terra em disputa e sua relação com políticos locais e órgãos do Estado. Para Macedo (2003, p. 5), os acampamentos constituem-se como uma linguagem social, que tem seus próprios processos de constituição e que variam de acordo com as conjunturas específicas:

[...] possuem as lonas (que cobrem as barracas) e as bandeiras (que indicam a instituição que organiza o acampamento) como principais símbolos e um modelo de organização social próprio, que vem se transformando ao longo do tempo e também comporta variações dessa representação social de caso para caso.

Nos últimos anos, temos visto mudanças significativas na configuração social dos acampamentos no Estado de São Paulo. Hoje em dia, por exemplo são poucos os que contam com uma população de moradores, a maioria são constituídos por famílias de assalariados que, por terem um emprego fixo, não moram nos acampamentos, mas mantêm barraca.

Sigaud (2000), L'Estoile e Sigaud (2006) e Wolford (2006) identificaram também, em acampamentos da Região Nordeste, indivíduos acampados envolvidos em múltiplas atividades econômicas. No caso dos acampamentos do noroeste do Estado de São Paulo, nos quais foi realizado o trabalho de campo, grosso modo, as principais atividades realizadas pelos acampados são: cortar ou colher cana, catar tomate, laranja ou outras 
frutas em fazendas próximas, cuidar do gado, plantar, cuidar de sítios ou chácaras, no caso de trabalhos no meio rural. E, no caso dos trabalhos realizados nas cidades: como pedreiros na construção civil, diaristas, mas também como comerciantes em feiras nas cidades, compra e venda de móveis usados, jardinagem, ou ainda serviços gerais prestados para empresas, comércio ou prefeituras locais, entre outros ${ }^{2}$. Essa circulação em curto prazo sempre fez parte do cotidiano dos acampamentos sem-terras, assim como as entradas e saídas, que é como nativamente os acampados se referem, seja a mudança para outro acampamento ou a desistência. E é comum que muitas dessas pessoas que desistem voltem ao mundo das ocupações de terra novamente meses ou anos depois se instalando em outro acampamento, e, nessa circulação, a maioria das vezes acabam reencontrando antigos vizinhos ou conhecidos de outros acampamentos pelos quais passaram ${ }^{3}$.

A novidade, portanto, não está nessa circulação em curto prazo ou nas múltiplas entradas e saídas, mas em uma mudança de regras para poder se manter como candidato à reforma agrária. Enquanto dez anos atrás a regra para se instalar em um acampamento era ser morador e "ficar debaixo da lona", hoje em dia é necessário ter uma barraca, mas não necessariamente morar no acampamento, podendo cumprir "regra de dois ou três dias", o que significa ficar no acampamento nos finais de semana ${ }^{4}$. Quer dizer que as regras implementadas

2 Informações do censo socioeconômico produzido como parte do projeto Jovem pesquisador "Formas de acampamento". As informações colhidas foram sistematizadas pela bolsista de treinamento técnico Aimée Shirozono.

3 Como mostrei em outro trabalho (Loera, 2015), nessas sucessivas entradas e saídas e circulação por acampamentos ao longo de meses ou anos configura tempo de acampamento, um know how do mundo das ocupações de terra. Essa experiência é muitas vezes categorizada pelos acampados através das designações nativas de novato, novo ou velho acampado. É importante mencionar que, no levantamento efetuado em três acampamentos de São Paulo, mais de $90 \%$ dos acampados já haviam passado por outros acampamentos.

4 A barraca é um elemento de extrema importância quando se está acampando, uma vez que é de posse dela que se pertence ao acampamento, ou seja, funciona como uma espécie de inscrição. Para ser considerado acampado de determinado acampamento, é 
pelos movimentos para se fazer parte de um acampamento têm sido flexibilizadas e adaptadas a essa circulação das famílias. Como nos lembra Malinowski (2003): as regras se adaptam à vida. No entanto, como veremos adiante, na dialética da produção da reforma agrária, o modo de vida dos acampamentos também vai sendo adaptado às exigências do Estado.

A população intermitente ou de final de semana é localmente conhecida como apoio ou andorinha. Por outro lado, os acampamentos vêm sendo instalados próximos a pequenas cidades do interior, atraindo uma população local que "mora" na cidade, mas passa a manter uma barraca e circular diariamente pelo acampamento. Essa modalidade de acampado é conhecida por alguns acampados como pardal.

Seu Cido, acampado andorinha, me explicava que essa designação faz referência ao passarinho marrom que faz ninho nos postes de luz das cidades, que gosta de morar na cidade e não gosta de voar muito longe para procurar 34 comida. E ainda fazia uma distinção em relação aos andorinhas que "procuram andar mais longe". Também, segundo Cido, "os pardal são muito barulhentos", fazendo referência ao fato de que os acampados que não moram no acampamento, de alguma ou outra forma compensam o fato de não morar participando de todas as passeatas, marchas ou mobilizações organizadas pelo movimento.

Em 2009, um militante do MST vinculado à direção nacional do movimento, quando interrogado sobre as diferenças encontradas na organização e no perfil das famílias dos acampamentos mencionava:

$\mathrm{Na}$ atualidade, agora, estamos dialogando com essas formas de acampamento, de trabalho de base onde digamos [tem] o assalariado rural, os cortadores de cana... Como é que você vai condicionar algumas famílias a viver 
direto no acampamento? São formas que estão sendo repensadas e, se tiver condições de ter um acampamento dentro da cidade, qual que é o problema? (Assentamento Unidos da Vitória, SP, fevereiro de 2009).

Esse militante resumia como formas de acampamento a existência de uma heterogeneidade de acampamentos e das diferentes formas de operar e gerenciar os acampamentos de acordo com o perfil das famílias.

Segundo Ondetti (2006, p. 89), a presença de famílias de áreas urbanas, por exemplo, tem-se incrementado nos acampamentos (do MST) nos últimos anos; de acordo com esse autor, para o MST existem "vantagens organizacionais ao se realizar o recrutamento em cidades e áreas urbanas, onde os trabalhadores estão mais concentrados demograficamente e a vigilância dos proprietários de terras é limitada ou inexistente" ${ }^{5}$.

A pesquisa tem revelado que, no caso do MST, o trabalho de base realizado em cidades não necessariamente está relacionado com uma vantagem organizacional do movimento, mas com uma estratégia de ação para conseguir famílias que se ajustem aos critérios determinados pelos órgãos de governo encarregados da desapropriação de terras, critérios que pesam na seleção de assentados e que têm efeito já na conformação dos próprios acampamentos.

Como veremos adiante, esse é o caso de acampamentos que reivindicam uma mesma fazenda localizada na região oeste do Estado de São Paulo, uma área recentemente decretada como terra devoluta na última instância do Judiciário e onde poderão ser assentadas 250 famílias $^{6}$.

\footnotetext{
5 Todas as traduções de citações foram feitas por esta autora especialmente para este artigo.

6 Segundo informações do Itesp, a média de hectares por família em assentamentos da região é de 18 a 20 hectares. Caso a fazenda seja demarcada em 250 lotes, cada família terá direito aproximadamente a 19 hectares.
} 


\section{Os critérios}

Em 1985, no Estado de São Paulo foi decretada, pela Lei $\mathrm{n}^{\mathrm{o}} 4.957$, a conformação de comissões para selecionar os beneficiários de "recursos fundiários". Segundo essa lei, o procedimento de seleção é público e realizado no município em que se localiza o imóvel em disputa. A comissão, como determinado na lei, deve ser constituída por um representante do Instituto de Assuntos Fundiários (IAF) hoje Instituto de Terras do Estado de São Paulo (Itesp), um representante da Procuradoria-Geral do Estado, um representante da prefeitura municipal, um representante da câmara municipal, um engenheiro agrônomo da Secretaria de Agricultura, um representante dos trabalhadores rurais indicado pela Federação dos Trabalhadores do Estado de São Paulo (Fetaesp) e dois representantes da sociedade civil indicados também pela Federação. Em 1992 foi feita uma emenda a essa lei, pelo Decreto $\mathrm{n}^{\circ} 35.852$, para regularizar a inscrição de trabalhador rural como candidato a um lote em um projeto de assentamento, em que este deverá comprovar a sua residência permanente, por mais de dois anos ininterruptos na região do estado onde se localiza o imóvel rural que será destinado à reforma agrária ${ }^{7}$.

$\mathrm{O}$ antigo IAF transformou-se em Itesp em $1991 \mathrm{e}$, desde então, tem uma forte atuação na seleção de famílias que

\footnotetext{
7 O Incra (Instituto Nacional de Colonização e Reforma Agrária) definiu, a partir de 1998, uma normatização mais precisa da metodologia de seleção dos candidatos potenciais à reforma agrária, em que a identificação dos candidatos é realizada "a partir de listas previamente elaboradas nos 'sindicatos de trabalhadores rurais, nos movimentos sociais de trabalhadores, nos órgãos de extensão rural do município ou em outras entidades" (Caume, 2002, p. 44). Segundo esse autor (p. 45), nesse processo é solicitada uma série de informações a respeito dos candidatos e são estabelecidos, a partir desses dados, "critérios eliminatórios" e "critérios classificatórios" para se chegar aos "melhores candidatos para assentamento". Essa normatização mudou em 2005. Informações colhidas recentemente no Incra mostram que, além de os critérios terem sido mais bem definidos, a seleção das famílias é baseada nos dados do cadastro que os próprios candidatos devem fazer no Incra através do Sistema de Informação Nacional para Projetos de Reforma Agrária (Sinpra).
} 
irão ser assentadas quando a área em disputa é de domínio estadual. Esse instituto segue a normatização estabelecida pelo Incra; no entanto, tem autonomia para chamar representantes do Estado e da sociedade civil para formar comissões de seleção para o estabelecimento de projetos de assentamento.

Essas comissões têm vigência de dois anos e é montada uma comissão para cada área em disputa. No entanto, a comissão é válida para todo o município onde se localiza a área. Os membros da comissão estabelecem "critérios obrigatórios" e "critérios classificatórios" para selecionar as famílias. Estes últimos "são definidos de acordo com a realidade em que se encontram os candidatos cadastrados" (Itesp, 1999). A comissão se reúne várias vezes antes de ter uma lista definitiva com as famílias que serão beneficiadas com um lote de terra.

Como informando em documentos oficiais do Itesp (1999, 2005 e 2009), os critérios obrigatórios são: possuir idade acima de 21 anos, não ser funcionário público da ativa ou aposentado, não possuir estabelecimento comercial ou industrial, não possuir imóvel rural igual ou maior ao módulo do lote do assentamento, não possuir renda estável fora da agricultura, não ter sido beneficiado por programas de assentamento, possuir perfil de trabalhador rural, possuir a maior parte da vida dedicada à atividade rural, residir na região há dois anos no mínimo. Já os critérios classificatórios são: número de membros da família e força de trabalho e experiência agrícola. $\mathrm{E}$, finalmente, em alguns casos são atribuídos bônus aos candidatos que preencherem dois requisitos: estar acampado e morar no município do cadastro. A bonificação por cumprir esses critérios, pode, inclusive, conferir pontuação mais alta para o candidato do que o cumprimento dos critérios obrigatórios. No relatório da comissão constituída para uma área de um município do Pontal foram dados 6 pontos de bonificação ao critério de 
"2 anos de moradia fixa no município", o triplo de pontos dados à maioria dos critérios obrigatórios e classificatórios (Itesp, 1999). Estes dois últimos critérios (moradia no município e tempo no acampamento) são chamados pelas lideranças dos acampamentos, pelos próprios acampados e inclusive por representantes do Estado como: tempo de município e tempo de acampamento ${ }^{8}$.

Esses critérios, como constatado em trabalho de campo, podem ser negociáveis segundo a conformação da comissão. Prefeitos ou representantes de prefeituras das áreas em disputa parecem ter um peso considerável nas decisões da comissão e podem dar mais pontuação a certos critérios em detrimento de outros.

Um ex-ouvidor do Estado e antigo funcionário do Itesp explica o que aconteceu na conformação de uma comissão que ele acompanhou em um município da região do Pontal:

Teve uma disputa muito grande entre a prefeitura e o Itesp porque eles não queriam inserir, naquele momento, o pessoal do movimento (dos acampamentos), que é outro perfil. Tanto que o perfil que saiu das pessoas assentadas foi o perfil das pessoas da cidade. Porque a pontuação foi dada para as pessoas que residiam no município. A pontuação das pessoas

\footnotetext{
8 O tempo é um tema caro à antropologia e tem sido tratado por diversos autores como uma das dimensões da vida social, através da qual podemos ter acesso não somente às maneiras pelas quais os grupos se relacionam entre si, mas ao modo como hierarquizam suas experiências expressas em temporalidades distintas. Autores brasileiros, como Palmeira (2002) e seu "tempo da política" e Borges (2003) com seu "tempo de Brasília", têm debruçado suas análises sobre essa temática. Neste artigo, não aprofundarei nesse tema, pois precisaria de um empreendimento empírico e analítico maior para analisar como certos critérios e não outros são retomados pela população, classificados e temporalizados nesse contexto de disputa por terras. Aqui apenas me limitarei a esboçar algumas hipóteses a respeito de como esses critérios, transformados em tempos, de maneira geral, nos ajudam a entender a configuração de formas de acampamento e o encaminhamento da reforma agrária no Estado de São Paulo.
} 
por tempo de acampamento foi dada por tempo de residência no município. Porque o movimento (MST) não tava na comissão de seleção [...] Nesse caso em específico, o diretor do Itesp disse que não queria ninguém do movimento, e da sociedade civil ele indicou um padre da cidade que não tinha vínculo com o movimento [...]. Então o perfil daquele assentamento ficou como o da cidade, um perfil de pessoas muito idosas, porque o critério era ser do município e mais tempo de agricultura. Aí acabou pegando pessoas que eram funcionários de fazendeiros, ou que eram boia-fria, não importa a atividade, desde que exista um registro rural. Por exemplo, nesse acampamento (que disputava a fazenda) tinha muitos agregados, que são os filhos dos assentados. Eles concorreram, eles estavam acampados mas não conseguiram pontos de tempo de agricultura porque não tinham registro, não tinham como comprovar. O tempo de criança e de adolescente deles (na roça) não foi contado, só foi contado o tempo de trabalho. Então esse assentamento saiu com o perfil de pessoas da cidade. Então tem esses critérios e a autonomia da comissão de seleção (Município de Presidente Prudente. Entrevista em janeiro de 2011).

Outro funcionário do Itesp nos explicou que a composição da comissão dependia da "lógica da Direção do Itesp", e que geralmente o presidente da comissão é o presidente do Itesp e ele decide quem convidar.

Uma vez configurada a comissão, negociações, trocas e acordos entre representantes do Estado e movimentos têm início, podendo, inclusive, essas negociações levarem a criar ou pontuar a mais alguns critérios classificatórios, e mais, dessas negociações podem surgir também novos acampamentos. 
O representante do Itesp anteriormente citado explicou:

Na atualidade a influência do prefeito é muito grande, é o que acontece: ele quer dar uma pontuação maior primeiro para os munícipes, aí quando sai a área, ele com suas relações geralmente forma um acampamento também. Geralmente sai um acampamento com as relações dele ou indicam algum movimento ou o movimento sai com pessoas do município [...] Aparece uma bandeira branca às vezes ou fazem acordo com algum movimento [...] Ele pode, por exemplo, pegar o movimento do Zé Rainha que não tava na área, que não tava acampado e o prefeito pode fazer uma articulação. Dizer: "vem para cá que se você vier pra cá eu vou brigar por uma pontuação maior para seus acampados" (Município de Presidente Prudente. Entrevista em janeiro de 2011) ${ }^{9}$.

No que se refere à participação dos movimentos nessa 40 comissão, esse ex-funcionário explicava a dificuldade de todos os movimentos do estado de estarem representados nos processos de seleção ${ }^{10}$. Para ele, atualmente, são os movimentos mais organizados e articulados como o MST os que conseguem ter uma participação, e é precisamente através da pressão desse movimento que o tempo de acampamento figura ou não como critério a ser pontuado.

No mundo dos movimentos por terra no Estado de São Paulo circula uma forte crença na posição de destaque do MST, o que chamei da "crença do prestígio" (Loera, 2015). E é comum que prefeitos e outros representantes de gover-

\footnotetext{
9 Um levantamento quantitativo que fizemos em diferentes sedes de movimentos, instituições e órgãos de governo como parte da pesquisa - base deste artigo - revelou a existência de acampamentos independentes ou de bandeira branca em várias regiões do Estado de São Paulo, em alguns deles a bandeira branca indica que esse acampamento não está vinculado a nenhum movimento social.

${ }^{10}$ Segundo dados de 2009 do Data Luta do Núcleo de Estudos sobre a Reforma agrária (NERA), no período de 2000 a 2009, foram registrados 25 movimentos de luta pela terra.
} 
nos locais prefiram manter relações e acordos com o MST do que com outros movimentos, por considerá-lo um movimento mais organizado e articulado. Já para os acampados, muitas vezes, a decisão de aderir a um acampamento do MST passa pela crença de que terão mais chances de conseguir um lote de terra, precisamente pela posição de destaque desse movimento. No entanto, essa crença nesse mundo social tem uma base objetiva.

Conforme um funcionário do Itesp explicou: "sempre o movimento [MST] tenta fazer as articulações de chamar alguém do Ministério Público ou chamar alguns aliados para compor [a comissão]", e mesmo se nem sempre consegue, conforme nos disse o funcionário, de alguma maneira encontra uma brecha de ação e participação. Para esse funcionário, "Agora eles [do MST] têm quase todas as comissões, é difícil ter uma [comissão] que não tenha alguém do movimento”.

O movimento tem certa margem de negociação na implementação de uma política de distribuição de terras em relação aos seus acampados, negociação que depende da cadeia de interdependências recíprocas, dos aliados e das trocas, das alianças e articulações que conseguem movimentar nesse processo. Por outro lado, conforme tentarei mostrar etnograficamente, o ajuste do perfil dos acampados aos critérios pontuados pela comissão, como o tempo de município e tempo de acampamento é central para que a distribuição dos dons do Estado se efetive.

\section{Na luta pela terra... um puxa o outro}

A Fazenda Aparecida é propriedade de um ex-prefeito de uma das maiores cidades da região do Pontal ${ }^{11}$. Durante mais de dez anos, o dono manteve seguranças armados na área para evitar ocupações ou qualquer tipo de invasão na

\footnotetext{
${ }^{11}$ Como forma de preservar a identidade dos meus interlocutores e seu processo de luta, os nomes utilizados são fictícios, assim como o nome da fazenda em disputa e o nome dos acampamentos nos quais foi realizado o trabalho de campo.
} 
propriedade, mas, os movimentos pressionaram com mobilizações em áreas próximas, assim como com ocupações no Incra e nas sedes do Itesp para que a fazenda fosse vistoriada, pois é considerada pelos movimentos como "um símbolo de luta”. A área foi finalmente vistoriada e, em 2010, decretada como terra devoluta ${ }^{12}$.

Nesse mesmo ano, no dia 1 de abril, durante as jornadas de mobilização do Abril Vermelho ${ }^{13}$, mais de 200 famílias, entre homens, mulheres e crianças haviam ocupado uma área nas proximidades da fazenda. Um acampamento foi montado ao lado da sede do município, uma cidade com 3.699 habitantes (segundo dados do Censo Demográfico 2000, IBGE), na beira de uma pequena estrada vicinal que atravessa a cidade, a 13 quilômetros da entrada da fazenda ${ }^{14}$.

A ocupação e a montagem do acampamento foram organizadas pelo MST, que, em menos de um mês, conseguiu mobilizar principalmente acampados de outros acam42 pamentos da região para participarem da jornad ${ }^{15}$. Esse

12 O proprietário recorreu da decisão na última instância do Judiciário e o processo ainda está correndo. A decisão do decreto dessa fazenda como terra devoluta se soma aos mais de 92 mil hectares de terras decretadas devolutas na região nos últimos anos. Desde então, o número de ocupações de terras e montagem de acampamentos aumentou e surgiram novos movimentos. Só em 2009, foram 50 ocupações na região de 80 realizadas em todo o estado (NERA, 2009).

${ }^{13}$ As mobilizações organizadas pelo MST se intensificam nessa data, pois fazem parte da agenda anual a ser cumprida para lembrar algumas datas simbólicas do movimento. Neste caso, a morte de dezenove sem-terras ocorrida no Pará, em abril de 1996.

14 Desde 2001, diferentes movimentos de luta pela terra montam acampamentos à beira das estradas com o objetivo de contornar a medida provisória ( $\mathrm{MP} \mathrm{n}^{\circ} 2.183$ ) baixada pelo governo federal proibindo que áreas invadidas sejam vistoriadas pelo Incra por dois anos. Para as lideranças dos movimentos que promovem as ocupações, essa medida teve como objetivo frear a empreitada de ocupações e evitar o pipocar de acampamentos. Os movimentos conseguem "driblar" essa MP ocupando e montando acampamentos à beira das propriedades e não dentro delas. Para uma discussão mais apurada sobre as mudanças na legislação brasileira sobre o procedimento de distribuição de terras e sua relação com o MST e o Estado, ver Meszaros (2000).

${ }^{15}$ Jornada na região oeste do Estado de São Paulo é o termo usado pelos dirigentes dos movimentos e pelos participantes dos acampamentos para designar os protestos e as performances coletivas organizadas pelo movimento, como forma de reivindicar benefícios do Estado. Essas jornadas também designadas mobilizações podem ser ocupações de terra, marchas, caminhadas, ocupação de prédios públicos etc. 
processo de mobilização começou no dia 8 de março durante uma marcha em comemoração ao Dia Internacional da Mulher, que foi realizada em uma cidade próxima, localizada a aproximadamente 100 quilômetros do local da ocupação. Segundo relatos dos acampados, naquele dia um promotor da cidade anunciou para um grupo de militantes que participavam da marcha que a fazenda estaria "pronta para ser destinada a assentamentos para reforma agrária". Assim, militantes do MST vinculados à coordenação de frente de massa $^{16}$ do movimento aproveitaram o evento e a reunião de famílias acampadas de toda a região para começarem o processo de mobilização $o^{17}$.

As famílias mobilizadas para a ocupação vieram de outros acampamentos: o Batira, do Município de Rancharia, o Vitória, do Município de Presidente Bernardes, e o Eldorado, do Município de Cuiabá Paulista, todos municípios vizinhos ${ }^{18}$.

Macedo (2005) e Loera (2009) descrevem ocupações organizadas pelo MST acontecidas no Rio de Janeiro e Bahia, respectivamente. Ambos os autores mencionam que as estratégias de mobilização das famílias estão relacionadas com o tempo e os recursos que o movimento tem para organizar a mobilização. Macedo explica que, diante da urgência

\footnotetext{
${ }^{16}$ Os militantes do setor de "frente de massa" do MST são os que se encarregam de organizar o trabalho de base nos bairros, arregimentam as pessoas, fazem os contatos com lideranças locais, fazem as reuniões nas quais se explica para os novos acampados a arte da ocupação, conseguem os recursos materiais (caminhões, ônibus, marmitas, lona etc.) para as ocupações e levam as pessoas até o local da ocupação.

${ }_{17}$ Mobilização nesse contexto também pode designar o processo que é vivido pelos participantes antes do momento da ocupação, isto é, troca de informações, deslocamento e movimentação dos participantes da ocupação, reuniões, visitas preliminares ao local da ocupação etc.

${ }_{18}$ A região do Pontal compreende 21 municípios, são eles: Alfredo Marcondes, Álvares Machado, Caiuá, Emilianópolis, Estrela do Norte, Euclides da Cunha Paulista, Marabá Paulista, Mirante do Paranapanema, Narandiba, Piquerobi, Pirapozinho, Presidente Bernardes, Presidente Epitácio, Presidente Venceslau, Ribeirão do Índios, Rosana, Sandovalina, Santo Anastácio, Santo Expedito, Tarabaí e Teodoro Sampaio.
} 
em realizar uma ocupação e da ausência de recursos para realizar um trabalho de base prolongado que consiga juntar o número desejado de famílias, a estratégia adotada é aumentar o número de pessoas que costumam apoiar a ocupação.

Nesse caso, ela é realizada com um grupo formado essencialmente de militantes, assentados, simpatizantes e acampados de outros locais. [...] Quando as condições sociais daqueles que residem nas imediações do acampamento favorecem a entrada de novas famílias, a estratégia obtém o resultado esperado. Aos poucos, as famílias que entram substituem o grupo que realizou a ocupação, já que aqueles que a apoiaram retornam para seus locais de origem (Macedo, 2005, pp. 487-88).

No caso da ocupação e montagem de acampamento 44 no sul da Bahia, descrito por Loera (2009), a dinâmica de mobilização também foi essa.

Nos primeiros dias o novo acampamento foi mantido principalmente por assentados e velhos acampados da região [...]. O objetivo era, segundo os participantes da ocupação, renovar o acampamento; isso significava levar pessoas "novas" para "substituir" os "velhos" acampados e assentados, para que estes pudessem voltar para seus acampamentos e assentamentos de origem” (Loera, 2009, p. 86).

O processo de mobilização das famílias que formaram o acampamento nas imediações da fazenda Aparecida destoa um pouco do modelo descrito pelos autores citados, uma vez que, após montado o acampamento, outra estratégia foi seguida. A maioria das famílias dos acampamentos que acompanharam a ocupação pouco depois se instalou à beira da estrada e ficou nesse acampamento. Foi realizado 
trabalho de base na cidade vizinha e as famílias novas, originárias dessa cidade e que se instalaram no acampamento formaram mais dois grupos, a eles se juntaram alguns acampados que vieram principalmente de Cuiabá Paulista, Venceslau e Tarabaí, formando mais um grupo.

Segundo um velho acampado ${ }^{19}$, a população da cidade vizinha foi convidada para se juntar ao acampamento com o objetivo de fortalecer a luta e cumprir com os critérios. Nesse contexto, esse acampado se referia ao cumprimento dos critérios os quais acredita terão mais peso na hora de selecionar famílias que irão para a terra, dentre eles o tempo de município.

Em 2012, após um "racha” entre alguns acampados, trinta famílias saíram do acampamento deixando-o esvaziado. Nesse contexto, a coordenação do acampamento determinou que devia ser feito um trabalho de base em cidades próximas para atrair novos acampados. Em conversa com um militante do MST vinculado à direção estadual do movimento, ele explicitava a importância de trazer famílias dos distritos próximos, pertencentes ao município, para dentro do acampamento, pois esse critério pesaria na seleção das famílias. E mencionava não se sentir nem um pouco preocupado com um acampamento que havia sido montado pelo movimento do Zé Rainha nas imediações da fazenda durante as mobilizações do Janeiro Quente $^{20}$, realizadas em 2012, pois ele sabia que as famílias mobilizadas não eram do município, pelo que não representariam uma concorrência para suas famílias.

19 Como foi mencionado anteriormente, esse termo remete àqueles que já têm experiência na arte de acampar, seja por serem acampados de outros lugares, porque já passaram por vários outros acampamentos antes, ou porque já têm bastante tempo no acampamento.

${ }^{20}$ Zé Rainha é considerado dissidência do MST; ele organiza ocupações e acampamentos sob a bandeira do MST, mas o movimento é conhecido como MST da base e atua principalmente no Pontal e nos municípios de Andradina e Araçatuba. Esse movimento é o principal concorrente do MST em número de ocupações no Pontal. Zé Rainha, em janeiro de 2010, propôs uma jornada de mobilizações que chamou de Janeiro Quente e que repetiu novamente em 2011 e 2012. 
Algumas famílias do acampamento não se sentiam tão tranquilas a respeito da concorrência por vagas na Fazenda Aparecida. Silvana, moradora do acampamento, que acampava junto com seus filhos, marido, duas irmãs e seu pai, se mostrava preocupada com as negociações que estavam sendo feitas pelos dirigentes do acampamento com o prefeito da cidade próxima, pois havia escutado boatos de que o prefeito ficaria com 100 vagas na fazenda para colocar famílias indicadas por ele, pelo que ficariam somente 150 vagas que seriam disputadas entre famílias acampadas no seu acampamento e famílias de mais dois acampamentos próximos, também organizados pelo MST. Algumas famílias desses acampamentos já haviam sido convidadas pela militância do MST para se juntarem ao acampamento. De fato, em junho 2012, no contexto de uma visita de campo, já estavam esperando a chegada da nova leva de acampados. Pouco antes do "racha" acontecer, havia 120 cadastros de acampados. Cada barra46 ca montada no acampamento corresponde a um cadastro. No período de cinco meses, setenta famílias haviam saído do acampamento. Quando isso ocorre, os cadastros desses acampados não são descartados pois, conforme informações dadas por uma das coordenadoras do acampamento, quando saírem os lotes na fazenda, esses ex-acampados com tempo de luta ainda poderão ser chamados para preencher vagas no assentamento, alguns deles, principalmente os do município, poderão ser contemplados.

Essa situação de "trazer de volta" acampados com tempo de luta parece ser uma prática recorrente quando se cria um projeto de assentamento. Foi o que aconteceu com várias famílias que contavam com anos de luta e que haviam acampado em acampamentos do Município de Andradina, tendo depois desistido. Aqueles que continuaram residindo na região foram localizados e indicados pela militância do MST para preencherem vagas remanescentes de um novo assentamento recém-formado no Município de Pereira Barreto. 
Desde 2012, aproximadamente a metade dos cadastrados do acampamento da Aparecida são de pessoas que mantêm residência fixa na cidade vizinha. Como o acampamento é literalmente do lado, esses acampados costumam circular todos os dias pelo acampamento, marcando presença com o coordenador do seu grupo e voltando depois para suas casas.

Os coordenadores do acampamento estabeleceram códigos para pontuar as famílias acampadas. Código 1 para os moradores (60 pontos por mês $=2$ por dia) e Código 2 para os não moradores ( 30 por mês $=1$ por dia $)$. Independente do grupo dentro do acampamento ao qual pertence os acampados, estes devem se cadastrar na secretaria do acampamento sob um desses códigos. Já as atividades (marchas, ocupações, passeatas etc.) fora do acampamento também são pontuadas. Cada atividade contabilizando uma pontuação distinta. No entender dos acampados, quem pontuar mais terá a possibilidade de escolher primeiro o lote desejado.

Essa pontuação contabiliza o total do tempo de acampamento (tempo de barraco + tempo de luta) e dependendo das negociações, trocas e articulações do movimento, a Comissão de Seleção que será montada para a Fazenda Aparecida poderá dar bonificação a esse critério. Um militante mencionava que, de fato, o movimento vai brigar para que esse critério seja pontuado (na comissão).

Em outro trabalho (Loera, 2015), descrevo, em acampamentos da região de Andradina, um sistema de pontuação parecido ao descrito anteriormente. No acampamento Famílias Unidas existia o caderno de pontos, um dispositivo local que servia para classificar - tendo como critério o tempo de barraco - os concorrentes a um lote de terra. Era levado a cabo um controle do tempo, mas não de um tempo qualquer, do "tempo" que se passa no barraco e especificamente no acampamento. Do ponto de vista dos acampados, 
o cumprimento de tempo de barraco contabilizado no caderno de pontos, de alguma forma contaria na hora de pleitear uma vaga em um assentamento.

Autores como Borges (2003), Macedo (2003) e Quirós (2006) observaram em outros contextos etnográficos a existência de dispositivos (listas) que servem para indicar quem receberá benefícios por parte do Estado. Essas listas, além de enumerar ou classificar quem receberá os benefícios, revelam também a existência de uma hierarquia, de um status diferenciado no interior dos grupos estudados. As listas identificadas por Borges entre os moradores de uma cidade-satélite de Brasília são dispositivos que mostram a relação que se tem com o Estado, no sentido de quem é mais apto para se tornar beneficiário dos bens disponibilizados, entre eles, o de maior valor é o lote. No acampamento estudado por Macedo (2003, p. 143), no Rio de Janeiro, foi estabelecida uma série de critérios "que consistiam num sistema de classi48 ficação das famílias acampadas, que estabelecia uma ordenação para o assentamento, caso não houvesse parcelas de terra para todas as famílias em um primeiro momento”. Nas listas que ficavam afixadas numa barraca localizada no centro do acampamento, era plasmada uma hierarquia das famílias, já que eram ordenadas segundo o cumprimento dos critérios. Já Quirós, na sua etnografia sobre participantes dos movimentos de desocupados em Buenos Aires, menciona a existência de listas nas sedes dos movimentos, que classificam as pessoas segundo o número de mobilizações de que participam e os benefícios recebidos em forma de cestas básicas disponibilizadas pelo Estado, proporcionais à participação.

Em vários acampamentos da região do Pontal, a pontuação também é colocada numa caderneta cujo controle fica nas mãos dos coordenadores do grupo, estes, por sua vez, passam as informações para a secretaria do movimento e, finalmente, essa informação é guardada junto com outros dados socioeconômicos e de origem do acampado. Em um 
acampamento organizado pelo MST da base (movimento liderado por Rainha), na região de Teodoro Sampaio, era a coordenadora geral do acampamento que, a cada semana, passava a pontuação dos acampados registrada nos cadernos dos coordenadores de grupo para um caderno pessoal, que guardava com zelo no seu barraco junto com todas as fichas de cadastro dos acampados. Algumas vezes, chamava uma pessoa de confiança do acampamento para que a ajudasse nessa tarefa. Inúmeras vezes, principalmente andorinhas que chegavam para participar das assembleias semanais passavam no barraco da coordenadora para perguntar sobre sua pontuação. Ela, tirando o caderninho de dentro de uma sacola plástica, mostrava a longa lista, e era sempre um momento de tensão, pois vendo a pontuação de outros, os andorinhas aproveitavam a oportunidade para reclamar que a participação em determinada mobilização ou que o cumprimento de mais dias no acampamento não tinha sido contabilizado.

A partir de 2002, o Incra criou o Sistema de Informação Nacional de Projetos de Reforma Agrária (Sinpra), um banco de dados que contém os cadastros de todos os candidatos à reforma agrária em nível nacional. Qualquer um que deseje um lote de terra deverá fazer um cadastro e mandar seus dados para o órgão federal. No caso do Estado de São Paulo, o Itesp também faz a mediação, dando suporte aos candidatos à reforma agrária, pois os cadastros on-line podem ser feitos nos escritórios do Itesp. Os cadastros podem ser atualizados e novos dados podem ser acrescentados depois de dois anos do primeiro cadastro. No caso de dois acampamentos na região do Pontal, os acampados estavam cadastrados inicialmente com referência a seus municípios de origem, tendo sido atualizados seus cadastros com a referência do município onde se encontravam acampados. Essa atualização é fundamental para comprovar os anos de residência no município, critério que pode ser indicado com bonificação pela comissão de seleção, tal como já acon- 
teceu com outros processos de seleção, na hora de indicar os beneficiários a um lote de terra.

Um funcionário do Itesp mencionava que, no caso dos acampamentos do Pontal, os cadastros dos acampados são levantados primeiro nos próprios acampamentos e depois levados até o Itesp para fazer os cadastros on-line. $\mathrm{O}$ funcionário, de maneira jocosa, mencionava que, quando via chegar um representante de algum acampamento com uma pilha de documentos no seu escritório, ele sabia que nesse dia sairia tarde do trabalho, pois tinha certeza de que teria de cadastrar o acampamento inteiro.

Em assembleia realizada em um dos acampamentos estudados, um dirigente do MST enfatizava que era imprescindível renovar o cadastro perante o Itesp, pois, em abril desse ano (2013), iriam se cumprir os dois anos de validade do cadastro. Sem a renovação, não poderiam ter acesso ao lote. Ainda, ele mencionava que o cadastro deveria ser feito 50 no Itesp de maneira individual ou em bloco, mas o número gerado da renovação deveria ser obrigatoriamente passado em bloco para os coordenadores de grupo. De maneira individual, os acampados não poderiam ter acesso ao benefício do lote. O militante ainda reclamava de "alguns espertinhos" que haviam querido se adiantar e fazer todo o trâmite antes, sem passar pelos coordenadores "só para passar na frente dos outros”, mas ele deixou claro que isso não seria possível, pois ele mesmo faria parte da comissão de seleção e conhecia "todos os acampados". Esse "conhecimento" lhe permitiria selecionar as famílias "que fizeram tudo direitinho".

Durante alguns meses, um computador foi instalado na secretaria do acampamento com o objetivo de ter uma base de dados com os cadastros dos acampados e sua pontuação. Esse é um dado que não é banal ou que deva passar despercebido na análise se pensarmos que o processo de reforma agrária é exatamente isso, um processo, não algo que 
está dado, mas vai sendo produzido cotidianamente; assim como não existe a priori um perfil de famílias demandantes de terra, mas esse perfil vai sendo moldado durante o próprio processo de luta. Sendo esses ajustes fundamentais e parte dos mecanismos sociais que permitem a engrenagem entre Estado e movimentos para tornar possíveis as políticas de distribuição fundiária. Esse argumento dialoga com as considerações de Rosa (2009) a respeito da categoria sem-terra. Como o autor demonstra, é uma categoria historicamente construída e que não existe como categoria autônoma em relação ao Estado. Surge no Rio Grande do Sul, no contexto do governo Brizola (1959-1963), com o sentido de orientar políticas de governo para pequenos agricultores, tendo sido apropriada e seu significado modificado depois por movimentos e organizações de trabalhadores rurais. E tendo sido o MST o movimento que "consagrou a categoria social 'sem-terra' como uma forma social de reconhecimento público" (Rosa, 2009, p. 197). Ainda esse autor critica a literatura acadêmica que vê o engajamento com os movimentos como uma reconversão de toda a história prévia dos sujeitos e como uma única experiência política. Como ele diz: "ela é uma, entre muitas outras" (Rosa, 2009, p. 219). Para esse autor, "após 30 anos do surgimento da categoria 'sem-terra', ela se institucionalizou como uma forma de negociação com os governos e não como identidade" (Rosa, 2009, p. 223).

Alguns movimentos, como o MST, têm sabido lidar com as regras e o perfil de famílias exigidas pelo Estado para a concessão de lotes de terra. Nos acampamentos organizados por esse movimento, o próprio cadastro dos acampados já é realizado no formato exigido pelo Estado. O movimento levanta os dados, faz os cadastros e os envia em massa para o Itesp ou para o Incra, isso com o objetivo, por um lado, de não enfraquecer o movimento com a demanda individual, conforme me disse um militante, e, por outro, como uma 
forma de "falar" a linguagem de demanda entendida pelo Estado para conseguir um dos dons mais valorizados no mundo das ocupações de terra: um pedaço de terra.

Recentemente, com a possibilidade da desapropriação de outra fazenda localizada em um município vizinho ao da Fazenda Aparecida, quarenta famílias, aquelas com mais pontuação do acampamento do MST, foram convidadas para montar um novo acampamento, localizado a 30 quilômetros de distância. Seu Oswaldo, que ficou acampado nas proximidades da Fazenda Aparecida, me explicava que essa estratégia "levaria todo mundo para a terra", ou seja, saindo qualquer uma das duas fazendas, nas palavras dele, "um puxará o outro". Ou seja, a lógica da redistribuição daqueles com mais tempo de acampamento para pleitear uma fazenda em outro município, e manter no município da Aparecida aqueles com menos tempo de acampamento, de alguma forma colocava as famílias de ambos os acampa52 mentos na possibilidade de atingirem a pontuação necessária para as duas fazendas, seja por tempo de acampamento ou tempo de município, e conforme estabelecida pela Comissão de Seleção. Afinal um puxará o outro.

Como vemos, é cumprindo com o tempo de acampamento que os acampados acabam cumprindo também com critérios obrigatórios e classificatórios avaliados e pontuados pelas comissões de seleção: perfil de trabalhador rural, residir na região há dois anos, tempo de agricultura, tempo de município e tempo de acampamento.

Volto então onde comecei: o tempo de acampamento parece ser uma chave analítica para entender a configuração de formas de acampamento, pois a origem, as características das famílias acampadas e dos acampamentos, o estatuto da terra em disputa e as relações entre movimento e políticos locais e representantes do Estado conformam variações de uma demanda coletiva que passa pela criação de um acampamento. Por outro lado, os dados etnográficos nos mostram 
que, na efetivação das políticas de distribuição fundiária, a participação dos movimentos é fundamental. O processo de reforma agrária se faz cotidianamente, cumprindo com seu tempo de acampamento: mantendo barraca, participando de mobilizações, de assembleias, circulando diariamente pelos acampamentos, marcando presença, preenchendo cadastros, negociando com representantes do Estado, em suma "um puxando o outro".

A abordagem etnográfica do mundo das ocupações de terras tem se mostrado bastante frutífera para apreender a dinâmica desse mundo social, evitando cristalizar e reificar processos sociais.

O trabalho de campo para a pesquisa que originou este artigo tem sido realizado simultaneamente em sedes de organizações e instituições estatais vinculadas ao mundo das ocupações de terra e em vários acampamentos localizados em diversas regiões do Estado de São Paulo e organizados por distintos movimentos: MST, MST da base, sindicatos e CUT. A compreensão das relações nesses diferentes espaços e sua análise deu origem à descoberta das diversas formas de acampamento.

A perspectiva de análise das formas de acampamento tem-se mostrado eficaz nessa empreitada e, além de apontar a riqueza ou limitação de certas categorias analíticas, nos desafia a levar a sério categorias nativas como instrumento de análise para descrever a dinâmica da vida social e suas múltiplas dimensões.

A meu ver, faz-se necessário pensar em modelos metodológicos que abordem de uma perspectiva relacional esses processos de mobilização e de demandas sociais, pois nos deparamos com situações etnográficas que perpassam os modelos preestabelecidos e as abordagens tradicionais. 
Ainda fica o desafio da continuidade da pesquisa para analisar etnograficamente a consolidação de projetos de assentamento da reforma agrária, pois os dados recolhidos em campo têm revelado que é precisamente nos acampamentos que se determina a configuração da organização, o perfil das famílias que comporão os assentamentos e a importância dos arranjos, trocas e relações entre movimentos e Estado, configurando "formas de assentamento".

A análise dessas relações é fundamental para entender a constituição e continuação de relações duradouras nos assentamentos rurais, a organização dos assentados e a gênese dos processos de conflito e cooperação entre as famílias assentadas que conformam modos de constituição de projetos de reforma agrária.

\section{Nashieli Rangel Loera}

é professora do Departamento de Antropologia e pesquisa54 dora do Centro de Estudos Rurais (Ceres) da Universidade Estadual de Campinas (Unicamp).

\section{BIBLIOGRAFIA}

BORGES, A. 2003. Tempo de Brasília. Etnografando lugares-eventos da política.

Rio de Janeiro: Relume Dumará. (Coleção Antropologia da Política). . 2004. "A fórmula do tempo: notas etnográficas sobre o 'tempo de

Brasília””. In: TEIXEIRA, C. C.; CHAVES, C. A. (orgs.). Espaços e tempos da política. Rio de Janeiro: Relume Dumará.

CAUME, D. 2002. A tessitura do "assentamento de reforma agrária". Discursos e práticas instituintes de um espaço agenciado pelo poder. Tese de doutorado em Ciências Sociais. Campinas, SP: Unicamp.

GRIMBERG, M.; FERNÁNDEZ, A. M. I.; ROSA, M. 2009. "Introducción". In: GRIMBERG, M.; FERNÁNDEZ, A. M. I.; ROSA, M. (orgs.). Estado y movimientos sociales. Estudios etnográficos en Argentina y Brasil. Buenos Aires: Antropofagia.

ITESP - Instituto de Terras do Estado de São Paulo. 1999. Ata da comissão de seleção dos projetos de Assentamento Fundiário de Marabá Paulista. 2005. Ata da Comissão de seleção do Município de Batatais. 
2009. Ata da comissão de seleção de beneficiários para o Município de Caiuá.

L'ESTOILE, B. de; SIGAUD, L. (orgs.). 2006. Ocupações de terra e transformações sociais. Rio de Janeiro: Ed. FGV.

LOERA, N. 2006. A espiral das ocupações de terra. São Paulo/Campinas: Polis/Ceres. 2009.Tempo de acampamento. Tese de doutorado em Antropologia Social. Campinas, SP: Unicamp. 2010. "Encampment time: an anthropological analysis of the land occupations in Brazil". The Journal of Peasant Studies (on-line), n. 37, pp. 285-318.

. 2011. "Tempo de luta". In: GRIMBERG, M.; MACEDO, M.;

MANZANO, V. (orgs). Antropología de tramas políticas colectivas: estudios en Argentina y Brasil. Buenos Aires: Universidad de Buenos Aires; Antropofagia.

. 2013. "Compromissos, dívidas e dons entre acampados, assentados, movimentos e Estado”. In: MENEZES, M.; PIETRAFESA de GODOI, E. (orgs.). Uma terra para se viver: colonos, assentados e quilombolas. São Paulo: Anablumme/CNPq. 2015. Tempo de acampamento. São Paulo: Ed. Unesp.

MACEDO, E. M. 2003. "Zé Pureza”. Etnografia de um acampamento no norte fluminense. Tese de doutorado em Ciências Sociais. Niterói, RJ: UERJ, . 2005. "Entre a 'violência' e a ‘espontaneidade': reflexões sobre os processos de mobilização para ocupações de terra no Rio de Janeiro". Revista Maná, Rio de Janeiro, Relume Dumará, PPGAS/Museu Nacional, v. 11, n. 2, pp. 473-97.

MALINOWSKI, B. 2002. "Théorie ethnographique du langage". In: Les jardins de corail. Paris: La Découverte. . 2003. Crime e costume na sociedade selvagem. Brasília: UnB.

MESZAROS, G. 2000. "Taking the land into their hands: the landless workers' movement and the Brazilian State". Journal of Law and Society, v. 27, n. 4 , pp. $517-41$.

NERA - Núcleo de Estudos sobre Reforma Agrária. 2009. Relatório Brasil. Dataluta. Universidade Estadual Paulista “Júlio de Mesquita Filho” (Unesp).

ONDETTI, G. 2006. "Repression, opportunity, and protest: explaining the takeoff of Brazil's landless movement". Latin American Politics and Society, v. 48, n. 2, pp. 61-94.

PALMEIRA, M. 2002. "Política e tempo: nota exploratória". In: PEIRANO, M. (org.). O dito e o feito. Ensaio de antropologia dos rituais. Rio de Janeiro: Relume Dumará. 
QUIRÓS, J. 2006. Cruzando la Sarmiento: una etnografía sobre piqueteros en la trama social del sur del Gran Buenos Aires. Buenos Aires: Ed. Buenos Aires (Série Etnográfica, Antropofagia, v. 1).

ROSA, M. 2009. "Sem-terra: sentidos e as transformações de uma categoria de ação coletiva no Brasil”. Lua Nova, n. 76, pp. 197-227.

SIGAUD, L. 2000. “A forma acampamento”. Novos Estudos Cebrap, n. 58, pp. 73-92.

WOLFORD, W. 2006. "The difference ethnography can make:

understanding social mobilization and development in the Brazilian Northeast”. Qualitative Sociology, v. 29, n. 3, pp. 335-52. 


\section{MECANISMOS SOCIAIS DA REFORMA AGRÁRIA EM SÃO PAULO PELO VIÉS ETNOGRÁFICO}

NASHIELI RANGEL LOERA

Resumo: Este artigo analisa etnograficamente a configuração de mecanismos sociais que permitem a produção e efetivação de políticas de distribuição de terra no Estado de São Paulo. Tendo como foco a dinâmica de organização e configuração de acampamentos liderados pelo Movimento dos Trabalhadores Rurais Sem Terra (MST) na região do Pontal de Paranapanema, o objetivo também é o de mostrar que as relações de cooperação estabelecidas entre representantes do Estado (Instituto de Terras do Estado de São Paulo Itesp), de governos locais e do movimento são fundamentais no processo de distribuição de dons do Estado, neste caso um lote de terra. No entanto, essas relações são condições sociais fundamentais para a configuração de formas de acampamento, i.e., variações de um modelo de demanda social coletiva contemporânea.

Palavras-chave: Mecanismos Sociais; Reforma Agrária; Tempo de Acampamento; MST; Estado.

\section{SOCIAL MECHANISMS OF AGRARIAN REFORIM IN SÃO PAULO}

Abstract: This article analyzes, from an ethnographic perspective, the configuration of social mechanisms that allows the production and achievement of land distribution policies in the State of São Paulo. Regarding on the dynamic and configuration of landless encampments of the MST in the Pontal de Paranapanema region I will demonstrate how cooperation relationship between State institutions as Itesp (Instituto de Terras do Estado de São Paulo), local governments and the MST are crucial in the process of State benefits distribution, in this case, a piece of land. This cooperation is part of the social conditions for the establishment 
of encampment forms as variations of a contemporary model of collective social demand.

Keywords: Social Mechanisms; Agrarian Reform; Encampment Time; MST; State.

Recebido: 22/12/2014 Aprovado: 08/05/2015 